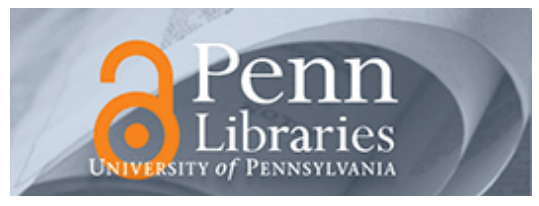

University of Pennsylvania

ScholarlyCommons

$11-2014$

\title{
An HBCU-Based Educational Approach for Black College Student Success: Toward a Framework with Implications for All Institutions
}

Marybeth Gasman

University of Pennsylvania, mgasman@gse.upenn.edu

Andrew T. Arroyo

Follow this and additional works at: https://repository.upenn.edu/gse_pubs

Part of the Higher Education Commons

\section{Recommended Citation}

Gasman, M., \& Arroyo, A. T. (2014). An HBCU-Based Educational Approach for Black College Student Success: Toward a Framework with Implications for All Institutions. American Journal of Education, 121 (1), 57-85. http://dx.doi.org/10.1086/678112

This paper is posted at ScholarlyCommons. https://repository.upenn.edu/gse_pubs/304

For more information, please contact repository@pobox.upenn.edu. 


\title{
An HBCU-Based Educational Approach for Black College Student Success: Toward a Framework with Implications for All Institutions
}

\author{
Abstract \\ This conceptual study builds an institution-focused, non-Eurocentric, theoretical framework of black \\ college student success. Specifically, the study synthesizes the relevant empirical research on the \\ contributions historically black colleges and universities (HBCUs) have made for black student success, \\ leading to an original model that all institutions can adapt to their contexts. Significantly, this is the first \\ HBCU-based theoretical model to appear in the academic literature. The study concludes with several \\ implications for research and practice, including testing the model and using it in institutional planning. \\ Disciplines \\ Education | Higher Education
}




\title{
An HBCU-Based Educational Approach for Black College Student Success: Toward a Framework with Implications for All Institutions
}

\author{
ANDREW T. ARROYO \\ Norfolk State University \\ MARYBETH GASMAN \\ University of Pennsylvania
}

\begin{abstract}
This conceptual study builds an institution-focused, non-Eurocentric, theoretical framework of black college student success. Specifically, the study synthesizes the relevant empirical research on the contributions historically black colleges and universities (HBCUs) have made for black student success, leading to an original model that all institutions can adapt to their contexts. Significantly, this is the first HBCU-based theoretical model to appear in the academic literature. The study concludes with several implications for research and practice, including testing the model and using it in institutional planning.
\end{abstract}

\section{Introduction}

Historically black colleges and universities (HBCUs) are a uniquely American institution. The Higher Education Act of 1965, as amended, defines an HBCU as any historically black college or university that was established and accredited (or making progress toward accreditation) prior to 1964, and whose principal mission was, and is, the education of black Americans. Cheyney University (ca. 1837) was founded first, followed by Lincoln University (ca. 1854), Wilberforce University (ca. 1856), and some 200 more by 1890 (Brown and Davis 2001; Gasman 2007a). Today they number 105 and represent roughly $3 \%$ of American postsecondary schools.

Beyond these basic facts, few topics in higher education are more polarizing

Electronically published September 18, 2014

American Journal of Education 121 (November 2014)

(C) 2014 by The University of Chicago. All rights reserved.

0195-6744/2014/12101-0003\$10.00 
than HBCUs. Observers often differ regarding their strengths, weaknesses, and even their relevance (Gasman 2006). As researchers ourselves with informed opinions on a variety of issues surrounding HBCUs, our goal here is not to satisfy or even address the breadth of concerns related to these schools. Instead, our goal is to begin a new line of theoretical HBCU-based research specifically related to the success of black students, while contributing a fresh perspective to all institutions that educate them.

The purpose of this article is to build a first-of-its-kind, institution-focused, theoretical framework that we call "an HBCU-based educational approach for black college student success." As we will discuss in more detail later, this will be a nuanced framework that makes no claim of homogeneity or perfection among HBCUs but instead synthesizes their aggregate positive work for black college students in a way that provides a model for all institutions to consider in their approach to educating this population, including HBCUs and nonHBCUs alike. Interestingly, the HBCU literature has developed for decades without the benefit of a single theoretical framework that is rooted in these schools and the work they do for black students. We contend that this has hindered the full depth of assessment, critique, learning, and improvement that could be possible if one were in place. Thus, our objective here is to take a step toward filling this theory gap by advancing the first HBCU-based theoretical framework in the literature to date.

We begin the article by offering a three-pronged rationale for our work. Next, we review and synthesize the relevant HBCU literature to ground the major components of the framework, and we introduce a conceptual model as a visual aid. We also offer theoretical reflections on the model. Finally, the article concludes with a variety of implications for researchers and practitioners. Some implications will deal directly with HBCUs themselves, and others will apply to all institutions.

Although we anticipate this article will spark debates of its own, we hope our rationale will be clear, the framework simple but comprehensive, and the implications and applications urgent and easily accessible so that this study might open new areas of theory-driven scholarship into the study and work of HBCUs and black student success more generally. If Lewin (1951, 169) was correct that "nothing is so practical as a good theory," and if Tierney's (1992, 603) sentiment was true, that "the purpose of our theoretical models is not

ANDREW T. ARROYO is assistant professor of interdisciplinary studies at Norfolk State University, a public HBCU. MARYBETH GaSMAN is professor of higher education in the Graduate School of Education at the University of Pennsylvania. She also serves as the Director of the Penn Center for Minority Serving Institutions. 
merely to describe the world, but to change it," then the present work might meet - and even exceed - expectations in the right hands.

\section{Rationale}

Before building the theoretical framework of an HBCU-based approach for black college student success, it is necessary to make our rationale clear on three counts: (a) why we focus on black college students, $(b)$ why this framework is institutional in nature rather than being student centric, and $(c)$ why we call it "HBCU based."

\section{Black College Student Success}

First, our rationale for advancing this framework around the specific topic of black college student success is rooted in the very pressing problem facing HBCUs and all of American higher education. Success can be a struggle for college students of every race and ethnicity across the spectrum of institutions (Arum and Roksa 2011; Tinto 2012); however, the struggle for success is particularly acute for too many black American students. Areas of concern include equitable access to college (Posselt et al. 2012), learning and overall development during college (Kimbrough and Harper 2006; Museus et al. 2011), and graduation from college (Knapp et al. 2011). Despite the impressive work of high-achieving black college students (Fries-Britt et al. 2010; Harper 2012; Jett 2013; McGee and Martin 2011; Palmer et al. 2010a), a race-based success gap persists.

Black student success, therefore, represents one of the more urgent issues in America today (Cokley and Chapman 2008). If our theory is found useful through rigorous testing and application, it could offer practitioners another tool for reversing this persistent quagmire.

\section{Institution Centric}

The second aspect of our rationale for creating this particular framework is that the broader student success literature lacks an institution-centric theory for black college student success. In order to understand this reason more fully, several comments are necessary.

Over recent years, scholars (Arroyo 2010; Cokley and Chapman 2008; Fleming et al. 2008; Guiffrida 2005, 2006; Kuh and Love 2000; Kumashiro 2000; Ladson-Billings 1995; Museus and Quaye 2009; Palmer et al. 2011; 
Petchauer 2009; Steele 1997; Watkins 2005) have introduced many conceptual contributions of varying sophistication and significance with relevance to black college student success. As a result, the literature provides a multifaceted theoretical base for working with this population. However, no extant conceptual work related to black student success deals sufficiently with institutional responsibility. Although the literature does contain comprehensive volumes that address institutional leaders and stakeholders (e.g., Gallien and Peterson 2005; Museus and Jayakumar 2012; Rovai et al. 2007), these do not constitute theoretical contributions in either form or function. A theory has particular uses because of its unique properties such as comprehensiveness, parsimony, connectivity, testability, and heuristic value together in a single discrete package (Bacharach 1989; Jaccard and Jacoby 2009; Shoemaker et al. 2004; Whetten 1989).

We must emphasize that the absence of an institutional theory for black student success is more than an academic research problem; it represents a practical problem since institutions are compulsory pipelines through which all black students must pass toward advanced learning and degree attainment. Many institutions seem content to practice what Harper (2009, 138) calls "institutional negligence" by failing to take seriously the education of blacks beyond lip service. Many institutions attempt to remediate underachieving black students as though they were ill by using a posture of "diagnose-andreact" (Withman and Bensimon 2012, 54). In other words, rather than focusing on what may be wrong at deeper levels within the institution and (re)forming an appropriate institutional culture to promote equitable student success organically, they attribute the problem to students who need fixing (Kuh and Love 2000; Tierney 1992). These approaches reinforce rather than reduce deficit stereotypes (Harper and Kuykendall 2012), perpetuating a view of blacks as substandard learners who are failing the institutions when the reverse might be true: the institutions are failing them. Meanwhile, high-achieving black students often are kept at arm's length as they struggle to prove their worth within a system that remains skeptical of their attainment (Harper 2013; McGee and Martin 2011).

Rather than blaming so-called underperforming black students, understanding the essential institutional components and processes for facilitating their success is imperative. Despite research that shows the significance of extracampus support systems such as family in encouraging black students (Guiffrida 2005; Harper 2012; Palmer et al. 2011), over 20 years ago Allen (1992, 40) challenged educators that the setting itself could "either facilitate or frustrate the academic achievement of Black students," and research suggests this has not changed (Museus and Quaye 2009). Outcalt and Skewes-Cox (2002, 344) made a similar argument that it is "important that we understand exactly how HBCUs create beneficial environments for their African American students," 
and Gallien (2007, 50) stated, "If administrators seek greater retention and satisfaction rates among minority groups, they should . . . begin to address the need for a more effective infrastructure." Our theoretical framework may aid in meeting these challenges.

Finally, it is important that we acknowledge the existence of other institutioncentric models in order to demonstrate that ours is not the first but also to show how ours is different. There is a precedent for thinking in institutional terms. For example, in a special issue of the Fournal of College Student Retention that was dedicated to institutional student success theories, Berger (2001) reviewed key organizational theories from 1970 through the 1990s (e.g., Clark et al. 1972; Kamens 1974; Meyer 1970). In the same issue, Kuh (2001) wrote an essay on the relationship between organizational culture and student persistence, and two other articles (i.e., Braxton and McClendon 2001; Braxton and Mundy 2001) offered some 67 recommendations for institutional practice. In a separate study, Berger and Braxton (1998) proposed a revised version of Tinto's (1993) student-centric interactionalist theory that included organizational components. Critically, however, these institutional theories emerge from a Eurocentric orientation, do not focus on black students, are not holistic in nature, and are not grounded in the work of HBCUs. In fact, Berger and Braxton (1998) acknowledged that a limitation of their integrated theory was the context in which they studied it: a highly selective, private research university with a population that was over $93 \%$ white. Similar majority contexts were central to the theories reviewed by Berger (2001; see also Kamens 1974), the sum of which essentially stated that the keys to student retention and persistence are institutional image, reputation, and social prestige, which promote a student's desire to stay in college. However, while these qualities deliver benefits to whites who are already privileged and positioned to gain access in the first place - not to mention to take advantage of the institution's social networks after graduation - they effectively keep the door closed to many historically marginalized students whose level of access and societal power were, and still are, lagging behind their majority counterparts. No higher educational model that was founded upon, draws from, or perpetuates Eurocentric power or privilege is capable of adequately serving historically marginalized populations. Exclusion is at their very foundation.

To summarize: many existing theories are either too focused on student responsibility or too Eurocentric in their institutional orientation. We see a need for a theory that directs institutions in embracing their responsibility for the equitable success of black students because such a theory is missing in the literature. Shaping institutions with this perspective is one of the great challenges facing education researchers, leaders, and other stakeholders today. When applied to black students, the right theory would ask questions such as, "What is right with African American students and what happens in those 
classrooms where teachers are successful with them?" (Ladson-Billings 2012, 117), and it would interrogate an institution's Eurocentric structures to ask in what ways they might be giving advantages or disadvantages to marginalized populations (Arroyo 2013b; Witham and Bensimon 2012). It would be more useful for black students than Eurocentric institutional theories, and it would stand against the integrationist viewpoint (Tinto 1975) that requires minority students to assimilate to an existing majority school culture rather than placing a burden of change on the school itself. HBCUs, given their long tradition of educating black students, are a logical place to turn for the generation of this new institutional theory.

\section{HBCU-Based}

Finally, our choice of the term "HBCU-based" is to underscore that the framework does not make any claims of perfect homogeneity among HBCUs, let alone espouse an idealistic claim of perfection. The framework is grounded in and supported by the best available empirical research regarding the contributions that HBCUs make to black college student success.

Therefore, we wish to be direct: we do not believe HBCUs are homogeneous or perfect; we know significant differences separate them; and some HBCUs have considerable deficiencies. Examples of difference include funding levels (Palmer et al. 2011), student profiles (Coaxum 2001; Palmer et al. 2011), and degree of emphasis on serving black students and on Afrocentric curricula (Cole 2006), not to mention variations in rankings. In addition to those differences, research indicates that HBCUs are imperfect, as are all colleges and universities. Some have difficulty communicating clear vision (Abelman and Dalessandro 2009; Guy-Sheftall 2006) or gaining positive media coverage for their accomplishments (Gasman and Bowman 2011), questionable and/or misunderstood leadership and governance (Gasman 201 1; Gasman et al. 2007; Minor 2004, 2008), unstable financial solvency compared to majority schools due in part to their historical legacy of marginalization and the predominant socioeconomic demographics of their students (Coupet and Barnum 2010; June 2003), and a continued need to improve the experiences of black undergraduate men (Kimbrough and Harper 2006) as well as lesbian, gay, bisexual, and transgender students (LGBT; Ford 2007; Patton 2011; Patton and Simmons 2008). To pretend they are homogeneous or perfect would be to disregard reality, and it goes against the objective of our theory.

It is also worth noting that in the present day, many scholars, leaders, and critics are debating HBCUs' future as "historically black" given their growing diversity. Currently 13\% of HBCU students are white, 3\% are Latino, and $1 \%$ are Asian American (Gasman 2013). Given the changing demographic 
of the nation - with large growth among Latinos and Asian Americans - it is more than likely that HBCUs, like other colleges and universities, will change significantly over the coming decades. These demographic changes are unsettling to some HBCU constituents - namely, older alumni - and welcomed by others - first and foremost, administrators concerned about dipping enrollments of black students (Gasman 2013).

With these clarifications made, it is a mistake to disregard HBCUs as relics or wholly ineffective. We contend that there is sufficient evidence to warrant the creation of a theoretical framework that is grounded in and supported by empirically substantiated contributions we know these schools have made or are making toward black college student success - that is, a theory that is HBCU based. The literature documents several positive similarities many HBCUs share that contribute a foundation to our theory. These include a common historical journey of struggle and victory (Allen and Jewell 2002; Brown and Davis 2001), a general mission of racial uplift (Gasman and Bowman 2011; Hirt et al. 2006), the provision of social capital to traditionally marginalized persons (Gasman and Jennings 2006), and an uncommon student experience that is particularly meaningful to blacks (Jett 2013; Outcalt and Skewes-Cox 2002; Thompson 2008). Ample research suggests that HBCUs as a group contribute to the success of black students in special ways (Gasman et al. 2010), and scholars even routinely champion them as exemplars that all institutions should follow for educating that population, including historically white institutions (HWIs) (Kim 2011; Walker 2011), community colleges (Hughes 2012), and even HBCUs themselves (Walker 2011). The presence of heterogeneity may complicate these research-based conclusions, but it does not constitute grounds to exclude their worth when discussing the theoretical and practical work they do. To the contrary, enough evidence of a distinct HBCU approach to educating black students exists that it is surprising that no theoretical framework has emerged in the literature until now.

Importantly, this discussion dovetails with a point that pertains to all theory, including ours. No credible work to build theory in any arena-whether in psychology, sociology, education, the study of organizations, or any other field - claims or requires homogeneity among its entire target population. Many models "are criticized because they are so simplistic that they appear to devalue that which they attempt to model . . . (and) because models by definition cannot represent all that it means to be human" (Shoemaker et al. 2004, 119). Individual units will always defy theoretical constructs. The rightful claim of theory is that studies of an entire population are enhanced when conducted through a structured lens that is based on available observations and reason, despite the fact that no theory accounts for all difference. Sigmund Freud, Jean Piaget, and Lev Vygotsky are just some examples of researchers whose theories have not depended on whether every human fits their para- 
digm, or even whether the academy has reached agreement as to their veracity, but whether their paradigm affords professionals a sound tool to use at their discretion as they work.

\section{Grounding the Framework}

As indicated, this theoretical framework is grounded in a synthesis of the extant literature related to the institutional influences HBCUs have been shown to exert on black college student success. This is an accepted method of theory building (Jaccard and Jacoby 2009) and has a precedent in Tinto's (1975) seminal work on student departure, among others. Creating the theory here is the first step in a protracted process of exploring, testing, and revising that is common to all new theories (Whetten 1989). Figure 1 depicts the framework in a conceptual model, and the subsequent sections ground the components of the framework in a selection of the relevant HBCU literature.

\section{Supportive Environment}

In figure 1, supportive environment is theorized to form the foundation of HBCUs' contributions to black student success. This environment moderates all other components and processes in the model. As supportive environment increases or decreases, the effectiveness of the entire model does the same.

The seminal statement on the HBCU supportive environment is found in Fleming's (1984) influential comparative study. She deemed an environment supportive when $(a)$ students have many opportunities for friendship with peers, faculty, staff, and counselors beyond the classroom; $(b)$ students are free to engage in extracurricular campus life, including satisfying positive power motives and holding leadership positions; and $(c)$ students feel a climate of academic development so that "an individual can achieve feelings of progress" (Fleming 1984, 19). Significantly, the black HBCU students in her study felt more supported on these measures than the black students at HWIs. Although Fleming's (1984) study is now dated, researchers have continued to find a positive environment for black students at HBCUs (e.g., Allen et al. 1991). This research has found greater levels of campus interpersonal relationships and social networking than their black HWI peers (Davis 1991), wellness (Spurgeon and Myers 2010), and sense of family and brotherhood (Jett 2013).

Some research does complicate the notion of the HBCU supportive environment. The most salient comes from interviews with black males (Kimbrough and Harper 2006) and black LGBT students (Ford 2007; Patton 2011; Patton and Simmons 2008), who expressed times they felt little to no insti- 


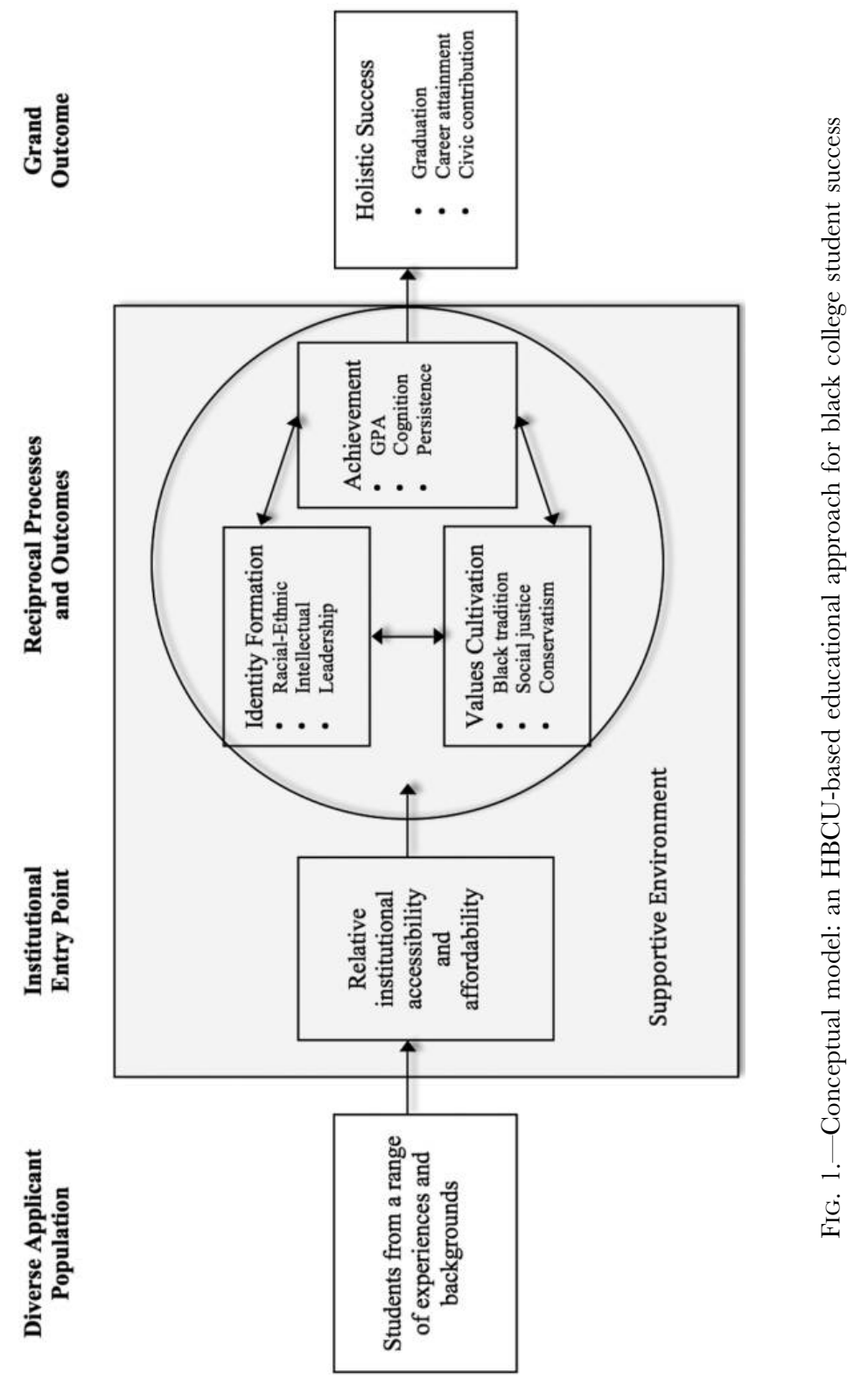


tutional support. However, in these studies, many of the same students who expressed a lack of institutional support in some areas still maintained that their HBCU was supportive overall. One reason given for this phenomenon was the environment, which boasts individuals with similar racial and ethnic backgrounds as well as similar cultural backgrounds. These similarities bring about feelings of safety and comfort, and this is particularly the case for samerace peers who can provide strength and encouragement in special ways even in cases where faculty or administrators let them down. ${ }^{1}$

\section{Institutional Entry Point: Relative Institutional Accessibility and Affordability}

In the context of a generally supportive environment, figure 1 posits that HBCUs welcome a diverse applicant population, including students from a range of experiences and backgrounds, through relatively accessible tuition and admissions policies. Some hopeful applicants are highly talented and affluent and could succeed anywhere, whereas others are decidedly underprepared, are from disadvantaged backgrounds, and have few other opportunities if any. Because of this feature, HBCUs contribute in the aggregate to equitable access to higher education. Moreover, they provide an example for educating a variety of students alongside each other.

From an economic standpoint, Clark (2009) called HBCUs "best bargains" because they educate students at lower than average cost. For example, private HBCUs' tuitions average $\$ 6,600$ less than similar non-HBCUs. Affordable tuition is important since $70 \%$ of $\mathrm{HBCU}$ students are considered low income and qualify for Pell Grants under federal measures (Quinton 2014), and over 85\% of all public HBCU students qualify for some form of financial aid (Ashley et al. 2009). Many are first-generation college students and attend school only part-time because of other responsibilities (Ashley et al. 2009; Gasman and McMickens 2010). Affordability is a vital service.

On the academic side, the notable distinction of HBCUs has been their flexibility in admissions relative to other institutions. Kannerstein $(1978,37)$ encapsulated this commitment adeptly with his famous explanation that the concern of HBCUs "is not with who gets in but what happens to them afterward." While academic entrance requirements have tightened at many HBCUs over the years, they generally retain comparatively open accessibility (Kim 2002).

Relative accessibility does open a debate about institutional inferiority. Opponents (Riley 2010; Vedder 2010) point to the lack of an Ivy League equivalent among HBCUs as proof of systemic inadequacies. According to U.S. Newes and World Report (2014), Spelman College, ranked first among HBCUs, falls to 65 in the national liberal arts colleges category; Morehouse College, 
ranked second among HBCUs, sinks to 126 among national liberal arts colleges; and Howard University, ranked third among HBCUs, drops to 142 in the national universities lineup. Vedder (2010) notes that not a single highly ranked HBCU appears in the top half of the Forbes ranking of 610 schools.

However, although the rankings are a matter of fact, what the rankings mean and the validity of the critics' interpretations are disputable. For instance, proponents counter by arguing that the Ivy League comparison is unrealistic. Not only were Ivy League and other elite HWIs forged from privilege (unlike HBCUs), but they also represent a minuscule percentage of all postsecondary schools and outrank literally thousands of HWIs. Moreover, the argument obscures the issue of choice. The best school for a particular student is not necessarily the highest-ranked school but the school that represents the ideal personal fit. Finally, the argument neglects the fact that admissions of blacks into selective and highly selective schools have suffered over recent decades compared to admissions of whites and Asians despite improved academic preparation (Posselt et al. 2012). Greater options for access are necessary if aspiring black collegians are to have the opportunity to realize their dream of a higher education. In fact, Palmer (2010) argues that restrictions on affirmative action will drive more blacks back to HBCUs in the future because of their accessibility relative to other schools. These counterperspectives illustrate just some of the reasons why devaluing HBCUs due to their relative accessibility is a questionable reaction both for the educational future of blacks and for all of American society.

We acknowledge that whereas access may have been viewed historically as a vital part of many HBCU missions, economic and political exigencies such as the need to regain students lost to HWIs or pressures of competition with non-HBCUs may be responsible for less egalitarian and benevolent motivations and changing policies. Nonetheless, the data continue to support the fact of accessibility relative to other schools, and it is reasonable to theorize a relationship between that policy and a supportive environment pending further studies to investigate their continued connection.

\section{Iterative Processes and Outcomes: Achievement, Identity Formation, and Values Cultivation}

In figure 1, achievement, identity formation, and values cultivation are conceived as both individual components and interacting processes, moderated by the supportive environment. We discuss the literature related to each individual component first, and then we offer additional theoretical remarks under a separate subheading.

Achievement.-Evidence already presented supports the notion that HBCUs 
contribute distinctively to access to college, and evidence will be presented later in this article on the mobility of HBCU students after graduation. The topic for this section is the contribution of these schools to scholastic or academic achievement during college.

In the first place, evidence suggests that HBCUs offer competitive learning opportunities. Some HBCUs have their own unique programs that could serve as replicable models (e.g., Brown 2008), and others have formed creative partnerships with majority schools to advance their students' education (Hammond and Davis 2005; Oder 2009; Stewart 2011; Virginia Consortium 2011; Walker et al. 2007). Many are vital pipelines for the production of new black $\mathrm{K}-12$ teachers, especially teachers who can have an impact on high-need schools (Irvine and Fenwick 2011). Students attending HBCUs can secure academic opportunities on par with many institutions.

Research also suggests that blacks attending HBCUs do at least as well academically as their HWI peers. Some studies have found that black students evidence the same level of academic achievement whether they attend an HBCU or HWI (Bohr et al. 1995; Cokley 2002; Kim 2002; Kim and Conrad 2006; Perna 2001; Wenglinsky 1996). This finding of no difference by institutional type is significant given the reduced resources of HBCUs combined with their greater average number of underprepared students (Kim 2002; Kim and Conrad 2006). Still other findings indicate that HBCUs actually produce higher levels of academic achievement among black students versus their HWI peers (Cokley 2000; Flowers 2002; Flowers and Pascarella 1999). Most importantly, no study has found a negative achievement effect of attending an HBCU.

A deeper question is how HBCUs are able to contribute uniquely to achievement. Some researchers (e.g., Gallien and Peterson 2005) contend that HBCUs are different in the teaching process itself, by incorporating traditional interventions for learning along with culturally relevant pedagogy (e.g., Boykin 1983; Watkins 2005). Additionally, figure 1 theorizes that achievement is a partial product of two other components in the model, identity formation and values cultivation.

Identity formation.- HBCUs generally seem to place a distinctive emphasis on formation of student identity, or self-concept, on at least three levels: racial/ ethnic, intellectual, and leadership. Some comparative studies with HWIs (e.g., Cokley 2002) have found greater academic (intellectual) confidence among samples of black HBCU students versus HWI students. HBCUs accomplish this in part by shielding students against negative stereotypes (Fries-Britt and Turner 2002; Perna et al. 2009). One way they do this is by providing ample same-race role models. ${ }^{2}$ Black instructors (Rucker and Gendrin 2003; Jett 2013) and external role models (Palmer and Gasman 2008; Thompson 2008) such as black guest speakers are said to help students feel comfortable in their 
own skin and improve as intellectuals. Indeed, HBCUs typically have more same-race role models than HWIs, especially when black faculty representation at majority schools can be $2 \%$ or less, leaving some departments with no black professors at all (Allison 2008).

Leadership formation is also a critical contribution of HBCUs to black student identity. Outcalt and Skewes-Cox (2002) found 69.1\% of black HBCU students were "satisfied" or "very satisfied" with leadership opportunities on campus compared to $57.3 \%$ of those attending an HWI. Jean-Marie (2008, 68) reported that black female HBCU leaders "regarded students as children of the community who are to be nurtured, groomed, and prayed for as leaders of the next generation." Ricard and Brown (2008) found similar commitments among HBCU presidents. Reddick (2006, 79) concluded HBCUs not only have an impact on their own graduates, but the impact extends through alumni to African American students "who may never set foot" on a black college campus.

It is worth pointing out that some authors (Arroyo 2010; Lott 2005; Wenglinsky 1996) have observed that black students in general-not just black students at HBCUs - already have a higher than average social consciousness and change-oriented leadership vision, opening the possibility that black students are predisposed toward leadership. In Wenglinsky (1996, 101), black students overall evidenced higher leadership aspirations than white students, but black HBCU students "are no more likely to aspire to positions of leadership" than black HWI students. Yet the evidence suggests that not all institutions are equally suited to develop this potential. Black HBCU students register higher educational aspirations, better graduate school preparation, and greater likelihood of becoming professionals than their HWI peers (Kim 2011; Wenglinsky 1996), which could mean they are more likely to enter society poised (by virtue of their training and the resources their positions afford) to become persons of influence in society. By emphasizing racial, intellectual, and leadership identity as they do, HBCUs seem to positively influence black student success during and after matriculation.

Values cultivation. - The final aspect of the theorized HBCU educational approach relates to the values component. HBCUs are known for attempting to cultivate a set of traditional African American moral principles and norms with the goal of developing citizens of competence and character. By many accounts, the traditional HBCU values system combines conservative and progressive components.

Progressivism is most obvious in HBCUs" emphasis on the "social piece" (Ricard and Brown 2008, 64), which tends to be absent from HWIs. Whereas the quintessential HWI focuses on research and scholarship, the typical HBCU sets its sights on societal change (Snydor et al. 2010). Stakeholders, from students (Douglas 2012; Lott 2005) to presidents (Ricard and Brown 2008), 
coalesce around this theme, particularly as it relates to rectifying racial and social injustices. In fact, Patterson et al. (2011) argue that the future relevance of HBCUs on the broader American postsecondary landscape may rest, at least in part, on their ability to carry forward this tradition of social change through creative programs in the area of service learning.

Conservatism is also seen in the traditional HBCU values system. JeanMarie $(2008,69)$ writes about HBCUs' "moral and social curriculum to ensure their students' success." Harper and Gasman (2008) identified three other aspects to HBCU conservatism: restrictions on sexuality and sexual orientation, restrictions on self-presentation and expression (e.g., clothing choices), and spoken and unspoken demands for positional subordination (i.e., lack of democracy in classrooms and clubs). Others (e.g., Ford 2007) have chronicled antigay treatment and policies at HBCUs nationwide, although the situation is improving (e.g., Cramer et al. 2013; Ford 2007; Patton 2011; Patton and Simmons 2008). This gives an indication of the complicated nature of HBCU values systems.

Unknown is the real impact of the HBCU values system-especially conservatism - on academic outcomes. Harper and Gasman (2008) expressed concern that parietal restraints might contribute to student frustration and departure, but the researchers did not formally test their finding of campus conservatism for a generalizable link to attrition. Also, studies (e.g., Crow 2007) on HBCU student departure have not mentioned campus conservatism as a factor. Although some students might leave because of the conservatism, it also is conceivable that a number of students persist because of it.

\section{Relationships between Achievement, Identity, and Values}

Figure 1 depicts achievement, identity, and values individually and in reciprocal relationship. On the basis of the existing studies already reviewed, some preliminary theoretical propositions indicate how these three elements of figure 1 can impact black student success. For example, keeping in mind that supportive environment is a moderating factor:

- Achievement and intellectual identity improve with each other.

- The HBCU conservative-progressive values system and racial identity influence each other.

- Achievement, racial identity, and intellectual identity work together to improve leadership identity.

In reviewing these and other potential connections within the model, it is important to underscore its comprehensive nature. A full analysis of all possible interactions between these three components is beyond a single article. Large- 
scale development and testing is needed (see "Implications"). Moreover, it is important to remember that the power of the model to impact student success is found less in any single component or process and more in the totality of all parts working together interdependently and holistically.

\section{Grand Outcome: Holistic Success}

Although modern HBCUs account for approximately 3\% of American postsecondary schools, they have produced a disproportionately high percentage of the black workforce. The United Negro College Fund (2008) reports that $70 \%$ of black dentists and physicians, $50 \%$ of black engineers, $50 \%$ of black public school teachers, and 35\% of black attorneys graduated from an HBCU. They are also pipelines for advanced educational attainment. Burrelli and Rapoport (2008) report that the top eight baccalaureate-granting institutions for blacks who go on to earn a terminal degree in science or engineering are HBCUs.

In terms of earnings and wages, while at least one analysis postulates a penalty for HBCU attendance (Fryer and Greenstone 2010), other evidence suggests no difference in earnings potential (Kim 2011) or even a benefit (Mykerezi and Mills 2008; Price et al. 2011). On account of these figures and others like them, HBCUs have been deemed responsible for creating the black middle class (Drewry and Doermann 2001). "Holistic success" is identified in figure 1 as the grand outcome according to the above measures, along with more intangible outcomes such as the development of moral persons and engaged citizens.

\section{Implications}

This study generated an institutional framework of an educational approach for black college student success that is grounded in the HBCU literature. Figure 1 contains some immediate implications for researchers and practitioners.

\section{For Researchers}

Researchers should be attentive to at least four salient implications of the framework for advancing the scholarship of HBCUs and Black student success.

Investigate the sameness or diversity of $H B C U$ s. - Although figure 1 is primarily a student success theory, a large-scale study is needed to investigate whether 
HBCUs are more homogeneous or heterogeneous in their educational approach, and whether figure 1 is an accurate conceptualization of that approach. Gaining this knowledge would assist in settling long-standing debates about the relative sameness or diversity of HBCUs. It would aid researchers, practitioners, and policy makers in knowing how to treat this group of institutions in their respective work. Future students also would benefit from this knowledge as they differentiate between higher educational options and make the best choices for them. Studying how students use this information could lead to an important contribution to the college choice literature (Freeman 2005; Strayhorn et al. 2012; Van Camp et al. 2009, 2010).

Unfortunately, no existing database contains the necessary information for addressing this topic. Fleming's (1984) and Allen et al.'s (1991) studies on HBCUs and black college students were the last large-scale investigations based on original data collection, and neither dealt with the homogeneity of educational approach. Consequently, a multiphase, mixed-methods study of national significance is needed to collect and analyze original data pertaining to two central questions: To what extent are HBCUs homogeneous in their educational approach for Black student success? and To what extent does figure 1 represent that approach (if it exists)?

Researchers who seek to develop such a study might consider including the following elements. (1) Qualitative data collection and analysis, especially indepth interviews with administrators, faculty members, and students from several HBCUs. Institutional sampling should reflect careful consideration so that a variety of HBCUs are included. The data obtained from a qualitative research phase can serve multiple purposes: $(a)$ to explore and refine figure 1 , (b) to inform the creation of a unique survey instrument designed for distribution to a nationally representative sample of HBCU stakeholders that is tailored to figure 1 , and $(c)$ to provide a complex understanding of the deeper processes at work in the educational setting of HBCUs. (2) Quantitative data collection and analysis involving all HBCUs or a nationally representative sample. This study would include (a) administering the specially tailored survey instrument and $(b)$ working with HBCU officials to compile an extensive set of basic student data (e.g., SAT/ACT scores, GPA, other relevant profile data) to improve the accuracy of self-reports from the survey on critical baseline measures.

To further nuance the results, researchers would need to juxtapose public and private HBCUs. Drewry and Doermann's (2001) comprehensive volume on private HBCUs demonstrates why thinking in these terms might be necessary. Researchers would also need to consider separating the 2-year HBCUs for their own analysis and perhaps even segment the schools by Coaxum's (2001) 10-cluster classification. It is possible that subcategories of HBCUs are homogeneous or heterogeneous in ways others are not. 
Test the causality and efficacy of this educational approach. - A separate but related analysis is needed to convert figure 1 from a conceptual model to a path model and to analyze the causal relationships that it suggests produce black student success. Establishing direct causality always is difficult, and even more so in the case of student success where extrainstitutional factors such as student academic preparation (Fleming et al. 2008) and home community support (Guiffrida 2005; Harper 2012; Palmer et al. 2011) are also known determinants. If figure 1 is found efficacious through rigorous testing, it would open doors for practitioners to use it as a tool for reversing the persistent problems listed throughout this study.

Create an integrated model of institutional and individual responsibility.-Although we strenuously argue in this article for institutions to turn their focus inward, we do not deny the usefulness of student-centric models for understanding factors such as black student attrition (e.g., Strayhorn 2013). We do caution, however, that integration of our HBCU-based institutional model and a model of individual responsibility will only work if the latter is equally non-Eurocentric and holistic in nature. Thus, while we appreciate previous attempts at integrated models (e.g., Berger and Braxton 1998), we underscore their limitations for nonwhite populations. Guiffrida (2005, 2006) and Palmer et al. (2011) provide useful starting points for culturally appropriate student-centric models to integrate with figure 1.

Explore gendered versions. - Researchers also can conduct studies related to black women and men as distinct groups. If HBCUs are found even moderately homogeneous in educational approach, is the approach experienced equally by gender? Even if HBCUs are found thoroughly heterogeneous, is figure 1 as a stand-alone model equally effective for both groups? Studies have demonstrated the different experiences and levels of success that tend to differentiate women and men (Gasman 2007b; Harper and Kuykundall 2012; Kimbrough and Harper 2006; Lundy-Wagner and Gasman 2011; Palmer et al. 2009; Strayhorn et al. 2012). Thus, gendered frameworks may be necessary to capitalize on their differences to create even more beneficial educational approaches. A gendered model could be particularly salient for reaching black males, since even HBCUs continue to struggle with this group that lags behind all others. Figure 1 is an excellent starting point for such a model because it assumes an antideficit view of the student, which is particularly lacking in the way schools tend to treat black males (Harper 2009).

\section{For Practitioners}

The framework also carries significant implications for practitioners at both HBCUs and all institutions that educate black students. 
Incorporate the framework into a broader plan of institutional reform. - As the diversity of America increases, every higher educational institution across this nation needs an active, ongoing plan to improve its culture of educational equity. Many institutions attempt to advertise a commitment to justice but lack the deeper culture - that is, values, beliefs, and traditions - to sustain it. True equity-oriented cultures "promote organizational actions aimed at intentionally and holistically targeting and addressing racial and ethnic disparities in educational opportunities, experiences, and outcomes" Jayakumar and Museus 2012, 17).

Black students must have a strong participatory voice in reforms for equityoriented cultures (Harper and Kuykendall 2012). Students have tremendous power to create transformational movements within institutions (Jayakumar 2012), and educational leaders would be wise to recognize and harness their energy. Figure 1 can assist in this process by providing a clear point of departure to facilitate dialogues between administrators and students that can lead to improvements in recruitment, admissions, pedagogy, student affairs, and outcomes (Arroyo 2013b). This study could serve as one of several joint readings that the different parties could use in order to add direction and value to their meetings.

This does not mean all institutions must adopt the theoretical HBCU model in full. Every school has a distinctive history, context, and vision that preclude such uniformity. Rather, figure 1 provides one additional tool among many for localized consideration and adaptation through a continuous process of organizational learning (Arroyo 2013b; Witham and Bensimon 2012). It may be that the framework excites debate, disagreement, and ultimately a departure from some or all of its tenets. And, to reiterate, this recommendation is relevant for all schools, including even HBCUs, which are not above the need for institutional reform and stand in ongoing want of new theories for guidance (Palmer et al. 2010b).

Be aware of unintended, expansion-related trade-offs. - In the course of institutional planning and reformation, figure 1 also serves as a constant reminder that growth-oriented initiatives, which are becoming more popular commensurate with the increased commoditization of American higher education, may not always be in the best interest of students. Vigorous expansion in areas such as enrollments, academic programs, or modes of delivery (i.e., online education) may require too many trade-offs that would diminish equitable outcomes (Arroyo 2014a). This is because, as figure 1 theorizes, the optimal educational approach for black students places a premium on qualitatively rich interaction between real people where human individuality, freedom, and high context interaction are practiced as a lived holistic philosophy. On the other hand, every level of expansion pushes an institution toward standardization, and standardization works against the ideals of figure 1 by imposing 
rules, routines, devaluations of the individual, and the like (Rodriguez et al. 2007).

Unfortunately, there is no precisely identifiable point where the trade-offs of growth might become too costly to sustain the holistic ideals of figure 1 . This means the process of institutional planning must be ongoing and iterative, where institutional leaders create their own dashboard of warning indicators to tell them if or when their expansion goals are going too far for students' own good (Arroyo 2009, 2014a). Black student success depends on institutions that stake their reputation on the success of the students rather than impressive enrollments or other forms of expansion that place $x$ objective ahead of raw student success. We contend that no institution is exempt from this governing principle.

Explore uses in the classroom.-Along with the macro implications figure 1 has for institutional reforms, it may have micro implications for the classroom. We concur with Tinto (2012), who argues that the classroom is the central venue where student success most often happens today. Therefore, even in cases where other sectors of an institution may fail black students, classrooms that incorporate at least some of its patterns can serve them well. Viewed through the prism of the model, effective classrooms might be conceived of as a function of combined focuses on achievement, identity formation, and values cultivation in a cooperative setting.

A necessary condition of this implication is a dedicated and engaged faculty body. As important as institutional leaders are for fully motivating a school toward equity-oriented change (Rubin 2011), it is often the case that strong visionary senior leaders are absent either because they are focused on other issues, or due to frequent turnover in administrative ranks. We suggest this makes faculty members the most pivotal players for creating holistic institutional conditions that facilitate student success. They can flourish under the right leadership, but they also can sustain quality classrooms under absentee or poor leadership. Also, the notion that faculty are central to the whole educational approach is supported throughout this article along with other studies that suggest they may be even more salient for student success than institutional type (Cokley 2000, 2002; Seifert et al. 2006; Wood and Turner 2011). Students tend not to attribute their success to a particular programor even typically to a senior administrator - but to a particular instructor or instructors whose personal touch made the difference.

This has two further implications. First, it means faculty members must do more than dispense content; their task is to instigate change. Enacting this change daily in the classroom reflects a very personal decision that should be worked out in his or her philosophy of teaching and presented to students at the outset of each semester. Figure 1 can provide a tangible point of reference in the process of developing such a personal philosophy, in conjunction with 
other useful research about structuring classroom environments and working to improve personal interactions with students (Arroyo 2010, 2013a; Cokley 2002; Dee and Daly 2012; Quaye and Chang 2012).

Second, it means institutions that are serious about black student success must invest in faculty members who are especially skilled at delivering the requisite educational experience. Many institutions have a select number of individual instructors who excel with students, but as Walker $(2011,27)$ points out, this is a problem because "One mentoring-minded individual at an institution can have a huge impact, but there are risks in terms of sustainability after that person leaves; having a critical mass of committed faculty is key." The ultimate effectiveness of an institution for black student success rests on the extent to which it has a deep field of faculty members that are both committed to and expert in the cause as a personal calling.

\section{Concluding Thought}

The framework introduced in this study is more than a conceptual project intended for an academic laboratory; it is intended to keep alive the vigorous discussion about what schools of higher education are and should be (really) doing about black student success. As new scholars enter academe with an interest in studying student success and the institutional environment, and especially the potential contribution of HBCUs in that equation, it is our hope that this framework can guide them in their process and that they will add to, modify, and support our framework. New research during rapidly changing times at HBCUs will certainly have the potential to contradict our framework as well.

\section{Notes}

1. Please note that findings pertaining to "same-race" interactions are based on the words and voices of students. "Same-race" does not imply that people are not diverse in terms of their ethnicity, religion, class, sexuality, or interests. However, given the dearth of black role models in academe, especially HWIs, being surrounded by a critical mass of people of one's race is empowering and comforting in the minds of the black students interviewed for various research studies. We also want to note that HBCUs have diverse faculties and staff, but they remain overwhelmingly black in their makeup, with blacks constituting over $65 \%$ of the faculty at HBCUs. In addition, $76 \%$ of HBCU students are black (Gasman 2013).

2. Please note that "same-race" does not imply that these faculty members are not complex in their identities. Overall the faculty at HBCUs is quite diverse in all aspects including race, ethnicity, country of origin, religion, gender, and sexuality (e.g., Arroyo 2014b). Still, there is ample research, based on student perspectives and perceptions, that demonstrates that having professors with similar backgrounds (most dominantly 
race), and who appear to be similar or are thought to be similar by students, leads to higher levels of confidence and increased success among students (Jett 2013; Rucker and Gendrin 2003).

\section{References}

Abelman, Robert, and Amy Dalessandro. 2009. "The Institutional Vision of Historically Black Colleges and Universities." Fournal of Black Studies 40 (2): 105-34.

Allen, Walter. 1992. "The Color of Success: African-American College Student Outcomes at Predominantly White and Historically Black Public Colleges and Universities." Harvard Educational Review 62 (1): 26-45.

Allen, Walter, Edgar Epps, and Nesha Haniff, eds. 1991. College in Black and White: African American Students in Predominantly White and in Historically Black Public Universities. New York: SUNY Press.

Allen, Walter Recharde, and Joseph Jewell. 2002. "A Backward Glance Forward: Past, Present and Future Perspectives on Historically Black Colleges and Universities." Review of Higher Education 25 (3): 241-61.

$\rightarrow$ Allison, Donnetrice. 2008. "Free to Be Me? Black Professors, White Institutions." Fournal of Black Studies 38 (4): 641-62.

Arroyo, Andrew. 2009. "Orienting Public Historically Black Colleges and Universities for the Future: Aligning Their Historic Mission with Appropriate Pedagogical Policy." Fournal of Race and Policy 5 (1): 67-76.

Arroyo, Andrew. 2010. "It's Not a Colorless Classroom: Teaching Religion Online to Black College Students Using Transformative, Postmodern Pedagogy." Teaching Theology and Religion 13 (1): 35-50.

Arroyo, Andrew. 2013a. "Diversity in Online Education." American Academy of Religion's Religious Studies News, May, http://www.rsnonline.org/index.php?option = com _content\&view $=$ article\&id $=1514 \&$ Itemid $=1675$.

Arroyo, Andrew. 2013b. "Enhancing Equity-Minded Institutional Self-Assessment/ Learning: A Precursor to Equitable and Poverty-Reducing College Student Learning and Development." Paper presented at the annual meeting of the American Educational Research Association, May, San Francisco.

Arroyo, Andrew. 2014a. "A Composite Theoretical Model Showing Potential Hidden Costs of Online Distance Education at Historically Black Colleges and Universities: With Implications for Building Cost-Resistant Courses and Programs." Online Fournal of Distance Learning Administration 17 (1), http://www.westga.edu/ distance/ojdla/ spring 171/arroyo 171.html.

Arroyo, Andrew. 2014b. "Consider the Source: An Open Letter to My Future CollegeGoing Friends." MSIs Unplugged: The Real Story of Minority Serving Institutions, March, http://msisunplugged.com/2014/03/18/consider-the-source/.

Arum, Richard, and Josipa Roksa. 2011. Academically Adrift: Limited Learning on College Campuses. Chicago: University of Chicago Press.

Ashley, Dwayne, Marybeth Gasman, Ronald Mason, Mary Sias, and George Wright. 2009. "Making the Grade: Improving Degree Attainment at Historically Black Colleges and Universities." United Negro College Fund, http://www .thurgoodmarshallfund.net/images/pdf/whitepaper09.pdf.

$\rightarrow$ Bacharach, Samuel. 1989. "Organizational Theories: Some Criteria for Evaluation." Academy of Management Review 14 (4): 496-515.

$\rightarrow$ Berger, Joseph. 2001. "Understanding the Organizational Nature of Student Persis- 
tence: Empirically-Based Recommendations for Practice." Fournal of College Student Retention 3 (1): 3-21.

$\rightarrow$ Berger, Joseph, and John Braxton. 1998. "Revising Tinto's Interactionalist Theory of Student Departure through Theory Elaboration: Examining the Role of Organizational Attributes in the Persistence Process." Research in Higher Education 39 (2): 103-19.

Bohr, Louise, Ernest Pascarella, Amaury Nora, and Patrick Terenzini. 1995. "Do Black Students Learn More at Historically Black or Predominantly White Colleges?” Journal of College Student Development 36:75-85.

Boykin, A. Wade. 1983. "On Academic Task Performance and Afro-American Children." In Achievement and Achievement Motives: Psychological and Sociological Approaches, ed. Janet Spence. San Francisco: W. H. Freeman.

$\rightarrow$ Braxton, John, and Shederick McClendon. 2001. "The Fostering of Social Integration and Retention through Institutional Practice." Fournal of College Student Retention: Research, Theory and Practice 3 (1): 57-71.

$\rightarrow$ Braxton, John, and Meaghan Mundy. 2001. "Powerful Institutional Levers to Reduce College Student Departure." Fournal of College Student Retention: Research, Theory and Practice 3 (1): 91-118.

$\rightarrow$ Brown, Jennifer. 2008. "Developing an English-as-a-Second-Language Program for Foreign-Born Nursing Students at an Historically Black University in the United States." Fournal of Transcultural Nursing 19 (2): 184-91.

$\rightarrow$ Brown, M. Christopher, and James Earl Davis. 2001. "The Historically Black College as Social Contract, Social Capital, and Social Equalizer." Peabody Journal of Education 76 (1): 31-49.

Burrelli, Joan, and Alan Rapoport. 2008. "Role of HBCUs as Baccalaureate-Origin Institutions of Black S\&E Doctorate Recipients." InfoBrief, NSF 08-319, National Science Foundation.

Clark, Burton, Paul Heist, T. R. McConnell, Martin Trow, and George Yonge. 1972. "Students and Colleges: Interaction and Change." Center for Research and Development in Higher Education, University of California, Berkley (ERIC Document Reproduction Service no. ED 069255).

Clark, Kim. 2009. "Why Black Colleges Might be the Best Bargains." U.S. Newes and World Report (February), http://www.usnews.com/education/articles/2009/02/09/ why-black-colleges-might-be-the-best-bargains.

$\rightarrow$ Coaxum, James. 2001. "The Misalignment between the Carnegie Classifications and Black Colleges." Urban Education 36 (5): 572-84.

$\rightarrow$ Cokley, Kevin. 2000. "An Investigation of Academic Self-Concept and Its Relationship to Academic Achievement in African American College Students." Fournal of Black Psychology 26 (2): 148-64.

$\rightarrow$ Cokley, Kevin. 2002. "The Impact of College Racial Composition on African American Students' Academic Self-Concept: A Replication and Extension." Fournal of Negro Education 71:288-96.

$\rightarrow$ Cokley, Kevin, and Collette Chapman. 2008. "The Roles of Ethnic Identity, AntiWhite Attitudes, and Academic Self-Concept in African American Student Achievement." Social Psychology of Education 11 (4): 349-65.

$\rightarrow$ Cole, Wade. 2006. "Accrediting Culture: An Analysis of Tribal and Historically Black College Curricula." Sociology of Education 79 (4): 355-88.

$\rightarrow$ Coupet, Jason, and Darold Barnum. 2010. "HBCU Efficiency and Endowments: An Exploratory Analysis." International Fournal of Educational Advancement 10 (3): 186-97.

Cramer, Elizabeth, Andrew Arroyo, and Charles Ford. 2013. "An Account of an Inter- 
Institutional Faculty Learning Community on Addressing Issues of Diversity and Oppression in the Classroom." Learning Communities Fournal 4:5-35.

Crow, Michael. 2007. "Stayers and Leavers among Newbies: Influences on the Early Departure of HBCU Freshmen." PhD diss., University of Michigan.

Davis, Robert. 1991. "Social Support Networks and Undergraduate Student Academic Success-Related Outcomes: A Comparison of Black Students on Black and White Campuses." In College in Black and White: African American Students in Predominantly White and in Historically Black Public Universities, ed. Walter R. Allen, Edgar G. Epps, and Nesha Z. Haniff. New York: SUNY Press.

Dee, Jay, and Cheryl Daly. 2012. "Engaging Faculty in the Process of Cultural Change in Support of Diverse Student Populations." In Creating Campus Cultures: Fostering Success among Racially Diverse Student Populations, ed. Samuel D. Museus and Uma M. Jayakumar. New York: Routledge.

$\rightarrow$ Douglas, Ty-Ron M. O. 2012. "HBCUs as Sites of Resistance: The Malignity of Materialism, Western Masculinity, and Spiritual Malefaction." Urban Review 44 (3): 378-400.

Drewry, Henry, and Humphrey Doermann. 2001. Stand and Prosper: Private Black Colleges and Their Students. Princeton, NJ: Princeton University Press.

Fleming, Jacqueline. 1984. Blacks in College: A Comparative Study of Students' Success in Black and in White Institutions. San Francisco: Jossey-Bass.

Fleming, Jacqueline, Albert Tezeno, and Sylvia Zamora. 2008. "The Retention and Planning Process at Texas Southern University: A Case Study.” In Historically Black Colleges and Universities: Triumphs, Troubles and Taboos, ed. Marybeth Gasman and Christopher L. Tudico. New York: Palgrave Macmillan.

Flowers, Lamont. 2002. "The Impact of College Racial Composition on African American Students' Academic and Social Gains: Additional Evidence.” Fournal of College Student Development 43 (3): 403-10.

Flowers, Lamont, and Ernest Pascarella. 1999. "Cognitive Effects of College Racial Composition on African American Students after 3 Years of College." Fournal of College Student Development 40 (6): 669-77.

Ford, Obie, III. 2007. "'This is Who I Am': A Phenomenological Study of the Lived Experiences of Black Gay Men with an Undergraduate Degree from a Historically Black College or University." PhD diss., Ohio University, College of Education.

Freeman, Kassie. 2005. African Americans and College Choice: The Influence of Family and School. New York: SUNY Press.

$\rightarrow$ Fries-Britt, Sharon, and Bridget Turner. 2002. "Uneven Stories: Successful Black Collegians at a Black and a White Campus." Review of Higher Education 25 (3): 315-30.

Fries-Britt, Sharon, Toyia Younger, and Wendell Hall. 2010. "Lessons from HighAchieving Students of Color in Physics." In New Directions in Institutional Research, no. 148, ed. Shaun R. Harper and Christopher B. Newman. San Francisco: Jossey-Bass.

$\rightarrow$ Fryer, Roland, Jr., and Michael Greenstone. 2010. "The Changing Consequences of Attending Historically Black Colleges and Universities." American Economic Fournal: Applied Economics 2 (1): 116-48.

Gallien, Louis. 2007. "School Cultural Influences." In Closing the African American Achievement Gap in Higher Education, ed. Alfred P. Rovai, Louis B. Gallien, and Helen R. Stiff-Williams. New York: Teachers College Press.

Gallien, Louis, and Marshalita Sims Peterson. 2005. Instructing and Mentoring the African American College Student: Strategies for Success in Higher Education. Boston: Allyn \& Bacon.

$\rightarrow$ Gasman, Marybeth. 2006. 'Salvaging 'Academic Disaster Areas': The Black College Response to Christopher Jencks and David Riesman's 1967 Harvard Educational Review Article." Journal of Higher Education 77 (2): 317-52. 
Gasman, Marybeth. 2007a. Envisioning Black Colleges: A History of the United Negro College Fund. Baltimore: Johns Hopkins University Press.

$\rightarrow$ Gasman, Marybeth. 2007b. "Swept under the Rug? A Historiography of Gender and Black Colleges." American Educational Research Fournal 44 (4): 760-805.

$\rightarrow$ Gasman, Marybeth. 2011. "Perceptions of Black College Presidents Sorting through Stereotypes and Reality to Gain a Complex Picture." American Educational Research Fournal 48 (4): 836-70.

Gasman, Marybeth. 2013. "The Changing Face of Historically Black Colleges and Universities." Center for Minority Serving Institutions, University of Pennsylvania, Philadelphia.

$\rightarrow$ Gasman, Marybeth, Benjamin Baez, Noah Drezner, Katherine Sedgwick, Christopher Tudico, and Julie Schmid. 2007. "Historically Black Colleges and Universities: Recent Trends (2007)." Academe 93 (1): 69-78.

Gasman, Marybeth, and Nelson Bowman III. 2011. "How to Paint a Better Portrait of HBCUs." Academe 97 (3): 24-27.

Gasman, Marybeth, and Michael E. Jennings. 2006. "New Research, New Questions: Social Foundations Scholarship on Historically Black Colleges and Universities (HBCUs)." Educational Foundations 20 (1/2): 3.

$\rightarrow$ Gasman, Marybeth, and Tryan McMickens. 2010. "Liberal or Professional Education? The Missions of Public Black Colleges and Universities and Their Impact on the Future of African Americans." Souls 12 (3): 286-305.

Gasman, Marybeth, Valerie Lundy Wagner, Tafaya Ransom, and Nelson Bowman. 2010. "Unearthing Promise and Potential: Our Nation's Historically Black Colleges and Universities." ASHE Higher Education Report 35, Association for the Study of Higher Education, Las Vegas.

$\rightarrow$ Guiffrida, Douglas. 2005. "To Break Away or Strengthen Ties to Home: A Complex Issue for African American College Students Attending a Predominantly White Institution." Equity and Excellence in Education 38 (1): 49-60.

$\rightarrow$ Guiffrida, Douglas. 2006. "Toward a Cultural Advancement of Tinto's Theory." Review of Higher Education 29 (4): 451-72.

$\rightarrow$ Guy-Sheftall, Beverly. 2006. "Shared Governance, Junior Faculty, and HBCUs." Academe 92 (6): 30-34.

Hammond, Pamela, and Bertha Davis. 2005. "From Idea to Graduation: The Evolution of the First PhD Program in a HBCU." ABNF Fournal 16 (6): 112-17.

Harper, Shaun. 2009. "Institutional Seriousness Concerning Black Male Student Engagement: Necessary Conditions and Collaborative Partnerships." In Student Engagement in Higher Education: Theoretical Perspectives and Practical Approaches for Diverse Populations, ed. Shaun R. Harper and Stephen John Quaye. New York: Routledge.

Harper, Shaun. 2012. "Black Male Student Success in Higher Education: A Report from the National Black Male College Achievement Study." Center for the Study of Race and Equity in Education, University of Pennsylvania, Philadelphia.

$\rightarrow$ Harper, Shaun. 2013. "Am I My Brother's Teacher? Black Undergraduates, Racial Socialization, and Peer Pedagogies in Predominantly White Postsecondary Contexts." Review of Research in Education 37 (1): 183-211.

$\rightarrow$ Harper, Shaun, and Marybeth Gasman. 2008. "Consequences of Conservatism: Black Male Students and the Politics of Historically Black Colleges and Universities." Fournal of Negro Education 77 (4): 336-51.

$\rightarrow$ Harper, Shaun, and John Kuykendall. 2012. "Institutional Efforts to Improve Black Male Student Achievement: A Standards-Based Approach." Change: The Magazine of Higher Learning 44 (2): 23-29.

$\rightarrow$ Hirt, Joan, Terrell Strayhorn, Catherine Amelink, and Belinda Bennett. 2006. "The 
Nature of Student Affairs Work at Historically Black Colleges and Universities." Fournal of College Student Development 47 (6): 661-76.

$\rightarrow$ Hughes, Bob. 2012. "Complementarity between the Transfer Goals of Community Colleges and Historically Black Colleges and Universities: Learning from History." Community College Fournal of Research and Practice 36:81-92.

$\rightarrow$ Irvine, Jacqueline Jordan, and Leslie Fenwick. 2011. "Teachers and Teaching for the New Millennium: The Role of HBCUs." Fournal of Negro Education 80:197-208.

Jaccard, James, and Jacob Jacoby. 2009. Theory Construction and Model-Building Skills: A Practical Guide for Social Scientists. New York: Guilford.

Jayakumar, Uma. 2012. "The Role of Student Agency, Student Empowerment, and Social Praxis in Shaping Supportive Cultures at Traditionally White Institutions." In Creating Campus Cultures: Fostering Success among Racially Diverse Student Populations, ed. Samuel D. Museus and Uma M. Jayakumar. New York: Routledge.

Jayakumar, Uma, and Samuel Museus. 2012. "Mapping the Intersection of Campus Cultures and Equitable Outcomes among Racially Diverse Student Populations." In Creating Campus Cultures: Fostering Success among Racially Diverse Student Populations, ed. Samuel D. Museus and Uma M. Jayakumar. New York: Routledge.

Jean-Marie, Gaëtane. 2008. "Social Justice, Visionary and Career Project: The Discourses of Black Women Leaders at Historically Black Colleges and Universities." In Historically Black Colleges and Universities: Triumphs, Troubles and Taboos, ed. Marybeth Gasman and Christopher L. Tudico. New York: Palgrave Macmillan.

$\rightarrow$ Jett, Christopher. 2013. "HBCUs Propel African American Male Mathematics Majors." Fournal of African American Studies 17 (2): 189-205.

June, Audrey Williams. 2003. "Endangered Institutions: Morris Brown's Plight Reflects the Financial Troubles of Small, Poorly Financed Black Colleges." Chronicle of Higher Education 49 (19): A24-A25.

$\rightarrow$ Kamens, David. 1974. "Colleges and Elite Formation: The Case of Prestigious American Colleges." Sociology of Education 44:354-78.

Kannerstein, Gregory. 1978. "Black Colleges: Self-Concept." In Black Colleges in America: Challenges, Development, and Survival, ed. Charles V. Willie and Ronald R. Edmonds. New York: Teachers College Press.

$\rightarrow$ Kim, Mikyong Minsun. 2002. "Historically Black vs. White Institutions: Academic Development among Black Students." Review of Higher Education 25 (4): 385-407.

$\rightarrow$ Kim, Mikong Minsun. 2011. "Early Career Earnings of African American Students: The Impact of Attendance at Historically Black versus White Colleges and Universities." Journal of Negro Education 80:505-20.

$\rightarrow$ Kim, Mikyong Minsun, and Clifton F. Conrad. 2006. "The Impact of Historically Black Colleges and Universities on the Academic Success of African-American Students." Research in Higher Education 47 (4): 399-427.

Kimbrough, Walter, and Shaun Harper. 2006. "African American Men at Historically Black Colleges and Universities: Different Environments, Similar Challenges." In African American Men in College, ed. Michael J. Cuyjet, 189-209. San Francisco: JosseyBass

Knapp, Laura, Janice Kelly-Reid, and Scott Ginder. 2011. "Enrollment in Postsecondary Institutions, Fall 2009; Graduation Rates, 2003 \& 2006 Cohorts; and Financial Statistics, Fiscal Year 2009: First Look." NCES 2011-230, U.S. Department of Education, National Center for Education Statistics, Washington, DC, last modified February 2011, http://nces.ed.gov/pubs2011/2011230.pdf.

$\rightarrow$ Kuh, George. 2001. "Organizational Culture and Student Persistence: Prospects and Puzzles." Journal of College Student Retention 3 (1): 23-39.

Kuh, George, and Patrick Love. 2000. "A Cultural Perspective on Student Departure." 
In Reworking the Student Departure Puzzle, ed. John M. Braxton. Nashville: Vanderbilt University Press.

$\rightarrow$ Kumashiro, Kevin. 2000. "Toward a Theory of Anti-Oppressive Education." Review of Educational Research 70 (1): 25-53.

$\rightarrow$ Ladson-Billings, Gloria. 1995. "Toward a Theory of Culturally Relevant Pedagogy." American Educational Research fournal 32 (3): 465-91.

$\rightarrow$ Ladson-Billings, Gloria. 2012. "Through a Glass Darkly: The Persistence of Race in Education Research and Scholarship." Educational Researcher 41 (4): 115-20.

Lewin, Kurt. 1951. Field Theory in Social Science: Selected Theoretical Papers, ed. Dorwin Cartwright. New York: Harper \& Row.

Lott, Joe, Jr. 2005. "Civic Orientation Predictors of Black Students: An Exploratory Study." PhD diss., Louisiana State University.

Lundy-Wagner, Valerie, and Marybeth Gasman. 2011. "When Gender Issues Are Not Just about Women: Reconsidering Male Students at Historically Black Colleges and Universities." Teachers College Record 113 (5): 934-68.

$\rightarrow$ McGee, Ebony, and Danny Martin. 2011. "You Would Not Believe What I Have to Go through to Prove My Intellectual Value!' Stereotype Management among Academically Successful Black Mathematics and Engineering Students." American Educational Research Fournal 48 (6): 1347-89.

Meyer, John. 1970. "The Charter: Conditions of Diffuse Socialization in Schools." In Social Processes and Social Structure, ed. William R. Scott. New York: Holt, Rinehart \& Winston.

$\rightarrow$ Minor, James. 2004. "Decision Making in Historically African American Colleges and Universities: Defining the Governance Context." Fournal of Negro Education 73 (1): $40-52$.

Minor, James. 2008. "Groundwork for Studying Governance at Historically Black Colleges and Universities." In Understanding Minority-Serving Institutions, ed. Marybeth Gasman, Benjamin Baez, and Caroline Sotello Viernes Turner. Albany: SUNY Press.

Museus, Samuel, and Uma Jayakumar, eds. 2012. Creating Campus Cultures: Fostering Success among Racially Diverse Student Populations. New York: Routledge.

Museus, Samuel, Robert Palmer, Ryan Davis, and Dina Maramba, eds. 2011. Racial and Ethnic Minority Students' Success in STEM Education: ASHE Higher Education Report. Hoboken, NJ: Jossey-Bass.

$\rightarrow$ Museus, Samuel, and Stephen John Quaye. 2009. "Toward an Intercultural Perspective of Racial and Ethnic Minority College Student Persistence." Review of Higher Education 33 (1): 67-94.

Mykerezi, Elton, and Bradford Mills. 2008. "The Wage Earnings Impact of Historically Black Colleges and Universities." Southern Economic Fournal 75:173-87.

Oder, Norman. 2009. "Cornell Library Expands HBCU Collections Project." Library Fournal 134 (14): 16.

$\rightarrow$ Outcalt, Charles L., and Thomas Edmund Skewes-Cox. 2002. "Involvement, Interaction, and Satisfaction: The Human Environment at HBCUs." Review of Higher Education 25 (3): 331-347.

$\rightarrow$ Palmer, Robert. 2010. "The Perceived Elimination of Affirmative Action and the Strengthening of Historically Black Colleges and Universities." Journal of Black Studies 40 (4): 762-76.

$\rightarrow$ Palmer, Robert, Ryan Davis, and Hilton Adriel. 2009. "Exploring Challenges that Threaten to Impede the Academic Success of Academically Underprepared Black Males at an HBCU." Fournal of College Student Development 50 (4): 429-45.

Palmer, Robert, Ryan Davis, and Dina Maramba. 2010a. "Popularizing Achievement: 
The Role of an HBCU in Supporting Academic Success for Underprepared Black Males." Negro Educational Review 61 (1-4): 85-106.

$\rightarrow$ Palmer, Robert, Ryan Davis, and Dina Maramba. 2011. "The Impact of Family Support for African American Males at an Historically Black University: Affirming the Revision of Tinto's Theory." Journal of College Student Development 52:577-97.

$\rightarrow$ Palmer, Robert, Ryan Davis, and Tiffany Thompson. 2010b. "Theory Meets Practice: HBCU Initiatives that Promote Academic Success among African Americans in STEM." Fournal of College Student Development 51 (4): 440-43.

$\rightarrow$ Palmer, Robert, and Marybeth Gasman. 2008. "It Takes a Village to Raise a Child: The Role of Social Capital in Promoting Academic Success for African American Men at a Black College." Fournal of College Student Development 49 (1): 52-70.

$\rightarrow$ Patterson, Gerrelyn, Yolanda Dunston, and Kisha Daniels. 2011. "Extreme Makeover: Preserving the HBCU Mission through Service Learning Pedagogy." Journal of African American Studies 17 (2): 154-61.

$\rightarrow$ Patton, Lori. 2011. "Perspectives on Identity, Disclosure and the Campus Environment among African American Gay and Bisexual Men at One Historically Black College." Fournal of College Student Development 52 (1): 77-100.

Patton, Lori, and Symone Simmons. 2008. "Exploring Complexities of Multiple Identities of Lesbians in a Black College Environment." Negro Educational Review 59 (34): 197-215.

$\rightarrow$ Perna, Laura. 2001. "The Contribution of Historically Black Colleges and Universities to the Preparation of African Americans for Faculty Careers." Research in Higher Education 42 (3): 267-94.

$\rightarrow$ Perna, Laura, Valerie Lundy-Wagner, Noah Drezner, Marybeth Gasman, Susan Yoon, Enakshi Bose, and Shannon Gary. 2009. "The Contribution of HBCUs to the Preparation of African American Women for STEM Careers: A Case Study.” Research in Higher Education 50 (1): 1-23.

$\rightarrow$ Petchauer, Emery. 2009. "Framing and Reviewing Hip-Hop Educational Research." Review of Educational Research 79 (2): 946-78.

$\rightarrow$ Posselt, Julie, Ozan Jaquette, Rob Bielby, and Michael Bastedo. 2012. "Access without Equity: Longitudinal Analyses of Institutional Stratification by Race and Ethnicity, 1972-2004." American Educational Research Fournal 49 (6): 1074-111.

$\rightarrow$ Price, Gregory, William Spriggs, and Omari Swinton. 2011. "The Relative Returns to Graduating from a Historically Black College/University: Propensity Score Matching Estimates from the National Survey of Black Americans." Review of Black Political Economy 38 (2): 103-30.

Quaye, Stephen, and Stephanie Chang. 2012. "Fostering Cultures of Inclusion in the Classroom: From Marginality to Mattering." In Creating Campus Cultures: Fostering Success among Racially Diverse Student Populations, ed. Samuel D. Museus and Uma M. Jayakumar, 88-105. New York: Routledge.

Quinton, Sophie. 2014. "When a 43\% Graduation Rate Means Success." The Atlantic, April 15, http://www.theatlantic.com/education/archive/2014/04/when-a-43graduation-rate-means-success/360672/.

Reddick, Richard. 2006. "The Gift That Keeps Giving: Historically Black College and University-Educated Scholars and Their Mentoring at Predominately White Institutions." Educational Foundations 20 (1): 61-84.

Ricard, Ronyelle Bertrand, and M. Christopher Brown. 2008. Ebony Towers in Higher Education: The Evolution, Mission, and Presidency of Historically Black Colleges and Universities. Sterling: Stylus.

Riley, Jason. 2010. "Black Colleges Need a New Mission.” Wall Street fournal, September 
28, http://online.wsj.com/article/SB10001424052748704654004575517822124077 834.html.

Rodriguez, Jacob, Steven Loomis, and Joseph Weeres. 2007. The Cost of Institutions: Information and Freedom in Expanding Economies. New York: Palgrave Macmillan.

Rovai, Alfred, Louis Gallien, and Helen Stiff-Williams, eds. 2007. Closing the African American Achievement Gap in Higher Education. New York: Teachers College Press.

$\rightarrow$ Rubin, Rachel. 2011. "Recruiting, Redefining, and Recommitting: The Quest to Increase Socioeconomic Diversity at Amherst College." Equity and Excellence in Education 44:512-31.

Rucker, Mary, and Dominique Gendrin. 2003. "The Impact of Ethnic Identification on Student Learning in the HBCU Classroom." Fournal of Instructional Psychology 30 (3): 207-15.

$\rightarrow$ Seifert, Tricia, Jerri Drummond, and Ernest Pascarella. 2006. "African-American Students' Experiences of Good Practices: A Comparison of Institutional Type.” Fournal of College Student Development 47 (2): 185-205.

Shoemaker, Pamela, James Tankard, and Dominic Lasorsa. 2004. How to Build Social Science Theories. Thousand Oaks, CA: Sage.

$\rightarrow$ Spurgeon, Shawn, and Jane Myers. 2010. "African American Males: Relationships among Racial Identity, College Type, and Wellness." Fournal of Black Studies 40 (4): $527-43$

Steel, Claude. 1997. "A Threat in the Air: How Stereotypes Shape Intellectual Identity and Performance." American Psychologist 65 (5): 797-811.

Stewart, Pearl. 2011. "HBCU Merger Proposals Persist Despite Fervent Opposition." Diverse: Issues in Higher Education (March), http://diverseeducation.com/article/ $14884 /$.

Strayhorn, Terrell. 2013. Theoretical Frameworks in College Student Research. Lanham, MD: University Press of America.

$\rightarrow$ Strayhorn, Terrell, Michael Williams, Derrick Tillman-Kelly, and Todd Suddeth. 2012. "Sex Differences in Graduate School Choice for Black HBCU Bachelor's Degree Recipients: A National Analysis." Journal of African American Studies 17 (2): 174-88.

$\rightarrow$ Sydnor, Kim Dobson, Anita Smith Hawkins, and Lorece Edwards. 2010. "Expanding Research Opportunities: Making the Argument for the Fit between HBCUs and Community-Based Participatory Research.” Journal of Negro Education 79:79-86.

Thompson, Pamela Felder. 2008. "On Firm Foundations: African American Black College Graduates and Their Doctoral Student Development in the Ivy League." In Historically Black Colleges and Universities: Triumphs, Troubles, and Taboos, ed. Marybeth Gasman and Christopher L. Tudico. New York: Palgrave MacMillan.

$\rightarrow$ Tierney, William. 1992. "An Anthropological Analysis of Student Participation in College." Fournal of Higher Education 63:603-18.

$\rightarrow$ Tinto, Vincent. 1975. "Dropout from Higher Education: A Theoretical Synthesis of Recent Research." Review of Educational Research 45 (1): 89-125.

Tinto, Vincent. 1993. Leaving College: Rethinking the Causes and Cures of Student Attrition. Chicago: University of Chicago Press.

Tinto, Vincent. 2012. Completing College: Rethinking Institutional Actions. Chicago: University of Chicago Press.

United Negro College Fund. 2008. "Fact Sheet," http://give.uncf.org/site/ DocServer/AEOS_about_uncf_factsheet.pdg?docID $=541$.

U.S. Newes and World Report. 2014. "Historically Black Colleges and Universities Ranking," http://colleges.usnews.rankingsandreviews.com/best-colleges/rankings/ hbcu

$\rightarrow$ Van Camp, Debbie, Jamie Barden, and Lloyd Sloan. 2010. "Predictors of Black Stu- 
dents' Race-Related Reasons for Choosing an HBCU and Intentions to Engage in Racial Identity-Relevant Behaviors." Journal of Black Psychology 36 (2): 226-50.

Van Camp, Debbie, Jamie Barden, Lloyd Sloan, and Reneé Clarke. 2009. "Choosing an HBCU: An Opportunity to Pursue Racial Self-Development." Fournal of Negro Education 75: 457-68.

Vedder, Richard. 2010. "Why Do We Have HBCUs?" Chronicle of Higher Education, http://chronicle.com/blogs/innovations/why-do-we-have-hbcus/27506.

Virginia Consortium Program in Clinical Psychology Catalog. 2011. Last modified May, 26 2014, http://sci.odu.edu/vcpcp/45714\%20VA\%20CONSORTIUMlores.pdf.

$\rightarrow$ Walker, Erica. 2011. "Supporting Giftedness: Historical and Contemporary Contexts for Mentoring within Black Mathematicians' Academic Communities." Canadian Fournal of Science, Mathematics and Technology Education 11 (1): 19-28.

$\rightarrow$ Walker, Tessa, Daniel Howard, Chanetta Washington, and Paul Godley. 2007. "Development of a Health Sciences Library at a Historically Black College and University (HBCU): Laying the Foundation for Increased Minority Health and Health Disparities Research." Fournal of the Medical Library Association 95 (4): 439-41.

Watkins, Angela Farris. 2005. "Cultivating the Education of African American College Students: A Learning Styles Approach." In Instructing and Mentoring the African American College Student: Strategies for Success in Higher Education, ed. Louis B. Gallien and Marshalita Sims Peterson, 122-27. Boston: Pearson Education.

$\rightarrow$ Wenglinsky, Harold. 1996. "The Educational Justification of Historically Black Colleges and Universities: A Policy Response to the US Supreme Court." Educational Evaluation and Policy Analysis 18 (1): 91-103.

$\rightarrow$ Whetten, David. 1989. "What Constitutes a Theoretical Contribution?" Academy of Management Review 14 (4): 490-95.

Witham, Keith, and Estela Mara Bensimon. 2012. "Creating a Culture of Inquiry around Equity and Student Success." In Creating Campus Cultures: Fostering Success among Racially Diverse Student Populations, ed. Samuel D. Museus and Uma M. Jayakumar. New York: Routledge.

$\rightarrow$ Wood, J. Luke, and Caroline Turner. 2011. "Black Males and the Community College: Student Perspectives on Faculty and Academic Success." Community College fournal of Research and Practice 35 (1-2): 135-51. 